\title{
Comparative study of four consolidation settlement estimation methods of a railway embankment.
}

\author{
Ahcène Benamghar ${ }^{1, *}$, and Mohamed Boudjellal ${ }^{2}$ \\ ${ }^{1}$ LTPiTE Laboratory, ENSTP, 1 Rue Garidi Kouba, Algiers, Algeria \\ ${ }^{2}$ ENSTP, 1 Rue Garidi Kouba, Algiers, Algeria
}

\begin{abstract}
Embankment is one of the oldest and most common constructions of public works due to its low cost, simplicity and good performance. This is why it is often required for economic reasons even if underlying soil is of poor quality. Meanwhile, this is not without risk, since we notice sometimes significant damages such as intolerable settlements, landslides and erosion. These risks are particularly dangerous in the case of railways where tolerances are mainly severe. In this work we propose a comparative study of four theoretical methods for estimating the consolidation settlement of a railway embankment. These methods are Terzaghi (1925), Asaoka (1978), Tan (1995) and Chunlin (2014). We applied each method to estimate the final settlement of the $15 \mathrm{~m}$ high embankment at PK245+000 of the railway under construction BoughezoulM'sila (Algeria).
\end{abstract}

\section{Introduction}

Algeria has recently initiated an ambitious program concerning basic infrastructure equipment like motorways and railways. So far, the biggest project in this grandiose program is unquestionably the east-west highway. This nerve center, with a length of $1216 \mathrm{~km}$, connects the Algerian-Tunisian border to the Algerian-Moroccan border through the capital, Algiers, and the main cities of the north .

Similarly, several railway lines were also finished and put into service linking many cities especially in the highlands region. Meanwhile other lines are still under construction in this region in order to strengthen the existing network, upgrade and make it more environmentally friendly. Indeed, the network will be fully electric and will respect the environment in a very rigorous set of specifications. Altogether there are almost $13000 \mathrm{~km}$ of rail lines to modernize or achieve which have been entrusted to the domestic firm Infrafer.

The rail line concerned in this study is situated in the highlands region of Algeria, connecting the city of Boughezoul, south of the capital Algiers, to the city of M'sila in

\footnotetext{
*Corresponding author: a.benamghar@enstp.edu.dz
} 
the east $(151 \mathrm{~km})$. This line is a part of a longer one called the "Highlands Ring" intended to link the main cities in this fast growing part of the country (Fig. 1).

The Highlands region, also known as High plains, is located in the Atlas Mountains in northern Algeria. A steppe-like natural area stretching more than $500 \mathrm{~km}$ in an eastwest direction from the Moroccan border to the Aures Mountains in the eastern part of the country

Topographically, the area is between $400 \mathrm{~m}$ of elevation in the west to $1300 \mathrm{~m}$ in the east. It mainly consists of undulating alluvial plains resulting from ancient sedimentary processes affecting the Tell and Saharan Atlas Mountains.

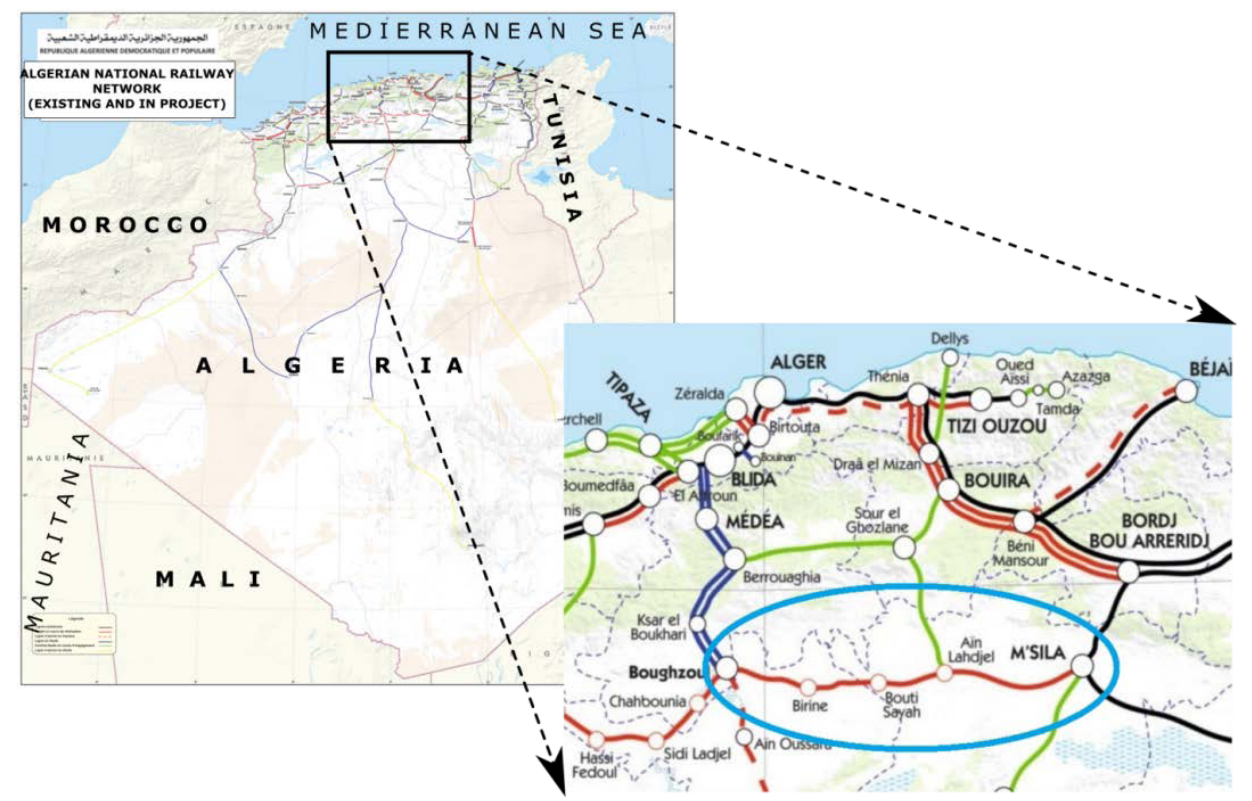

Fig. 1. Algerian railway network with a zoom on the study area. The Boughezoul-M'sila railway project is shown circled by an ellipse (bottom right) (original figures from ANESRIF).

Despite favorable topography for rail construction, there are places on the route of the project that pose challenges for engineers. One of these challenging problems is compressible soils which are very frequent in recent quaternary soils spreading in the region. The problem becomes particularly difficult when these soils must accommodate high embankments to fill topographic depressions.

The most important backfill on the route of the Boughezoul-M'sila line is located at PK245+000. It must have an exceptional height of $15 \mathrm{~m}$ on a compressible soil (wet and saturated gypsum clay). The purpose of this work was to study the final settlement of that soil in the future. This work was particularly interested in the consolidation settlement through a comparative study of four different theoretical methods. These methods are Terzaghi [1], Asaoka [2], Tan [4] and Chunlin [6]. 


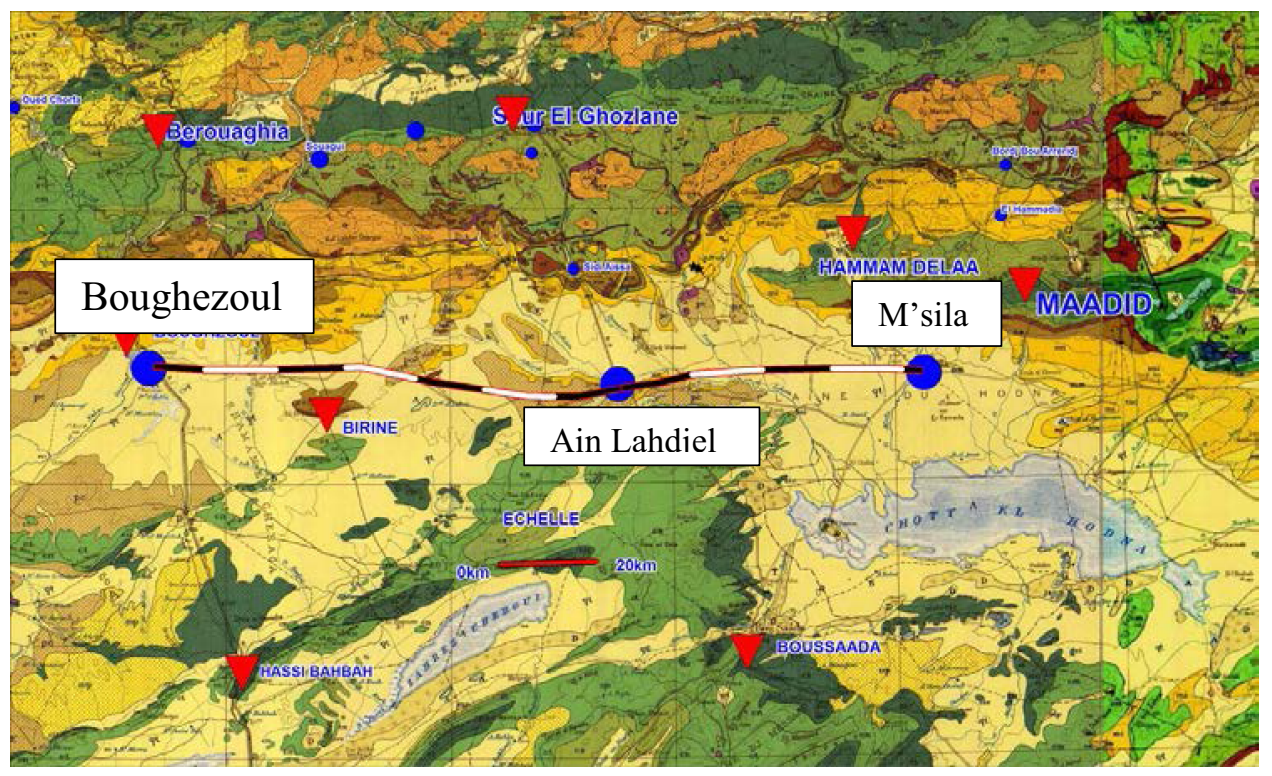

Fig. 2. Drawing of the Boughezoul-M'sila railway line. Extract from the geological map of Algeria [7] (1:500.000).

\section{Theory and method}

The compressibility phenomenon is often very slow and may extend over time, well after the establishment of the embankment. It can last for decades, mainly depending on the thickness of the compressible layer and its permeability. These vertical down deformations are known as "settlement".

\subsection{Magnitude of settlement}

According to Terzaghi's theory, the total settlement $\left(S_{\infty}\right)$ of a soil consists of primary settlement $\left(S_{p}\right)$, secondary settlement $\left(S_{s}\right)$ and settlement induced by lateral displacements $\left(S_{\text {lat }}\right)$. The primary settlement has two components: an immediate settlement $\left(S_{i}\right)$ and a deferred settlement associated with consolidation $\left(S_{c}\right)$. Hence the overall formulae $[8,9]$ :

$$
S_{\infty}=S_{p}+S_{s}+S_{\text {lat }}=S_{i}+S_{c}+S_{s}+S_{l a t}
$$

Where: $\quad S_{i}$ : immediate settlement,

$S_{c}$ : consolidation settlement,

$S_{s}$ : secondary settlement,

$S_{\text {lat }}:$ lateral displacement induced settlement

In order to estimate the final settlement, one should calculate separately each one of the four parameters of Eq. (1). Among all these parameters, only the consolidation settlement is the most difficult to estimate because it depends on the time. Each one of the four methods, used in this study, has its own approach to estimate this important variable.

The three other parameters $\left(S_{i}, S_{s}, S_{\text {lat }}\right)$ are the same for the four methods; we give in the following section the formulas to calculate them. 


\subsection{Immediate Settlement $S_{i}$}

According to Terzaghi this settlement is given by [6]:

$$
S_{i}=\frac{q}{E} \cdot B \cdot I
$$

Where: $\quad q$ : vertical stress applied to the foundation soil (KPa) [10]

$B$ : width of the loaded area $(\mathrm{m})$,

$I$ : influence coefficient depending on the embankment geometry and the compressible soil thickness,

$E$ : Young's modulus, estimated in our case using the oedometer modulus $E_{\text {oed }}$ : given by: $E=\frac{2}{3} E_{\text {oed }},(\mathrm{KPa})$.

\subsection{Secondary Settlement $S_{s}$}

In the PhD thesis of Akou [11] or Leroueil et al. [12], we can learn that the secondary settlement $S_{\mathrm{s}}$ mainly occurs at the end of consolidation for a time $t$ greater than $t_{100}$ which gives the following equation:

$$
S_{s}=C_{\alpha} \cdot H \cdot \log \left(\frac{t}{t_{100}}\right)
$$

Where: $t_{100}$ : time corresponding to the end of primary consolidation,

$C_{\alpha}$ : coefficient of creep,

$H$ : thickness of the compressible layer (m).

$t=2 \cdot \mathrm{t}_{100}$

\subsection{Lateral displacement induced settlement $S_{\text {lat }}$}

According to Akou [11], there is no way to calculate this settlement, but using Bourges and Mieussens [9] study concerning lateral displacement under embankments which allows to convert the volume corresponding to these movements into supplementary settlement:

$$
S_{\text {lat }}=0.11 \frac{D}{B} S_{\text {oed }}
$$

Where: $D$ : total height of the compressible layer $(\mathrm{m})$

$B$ : half-width of the embankment (m)

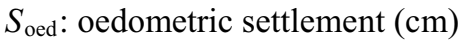

\section{Methods compared in this work}

This paper compared four theoretical methods in computing consolidation settlement. These are the well-known Terzaghi method [1], the Asaoka method [2], the Tan method [4] and the recently proposed Chunlin method [6]. In the following section are presented the main principles of each one. The related computation results can be found in the case study section, below. 


\subsection{Terzaghi method [1]}

In the two-dimensional case, consolidation settlement $S_{c}$ is calculated for the virgin compression zone. According to the stress-strain curve used, $S_{\mathrm{c}}$ is expressed by the following formulae [8]:

- Normally consolidated soil:

$$
S_{c}=C_{c i} \frac{H_{i}}{1+e_{0 i}} \log \left[\frac{\sigma_{v 0 i}^{\prime}+\Delta \sigma_{i}}{\sigma_{p i}^{\prime}}\right]
$$

- Over consolidated soil, where we can face two possibilities:

○ Fist case $: \boldsymbol{\sigma}_{\mathbf{v} 0}^{\prime}+\Delta \boldsymbol{\sigma}_{\mathbf{i}}<\boldsymbol{\sigma}_{\mathrm{p}}^{\prime}$

$$
s_{c}=c_{s i} \frac{H_{i}}{1+e_{0 i}} \log \left[\frac{\sigma_{p i}^{\prime}}{\sigma_{v 0 i}^{\prime}+\Delta \sigma_{i}}\right]
$$

$\circ \quad \underline{\text { Second case }}: \sigma_{\mathrm{v} 0}^{\prime}+\Delta \sigma_{\mathrm{i}}>\sigma_{\mathrm{p}}^{\prime}$

$$
S_{c}=C_{s} \frac{H_{i}}{1+e_{0 i}} \log \left[\frac{\sigma_{p i}^{\prime}}{\sigma_{v 0 i}^{\prime}}\right]+C_{c i} \frac{H_{i}}{1+e_{0 i}} \log \left[\frac{\sigma_{v 0 i}^{\prime}+\Delta \sigma_{i}}{\sigma_{p i}^{\prime}}\right]
$$

Where: $\Delta \sigma_{i}$ the stress due to embankment and road overload in the $\mathrm{i}^{\text {th }}$ layer on embankment axis,

$\sigma_{\mathrm{v} 0}^{\prime}$ : Effective stress due to the weight of land in the $\mathrm{i}^{\text {th }}$ layer on the axis of embankment, $\sigma_{\mathrm{pi}}^{\prime}$ : Pre-consolidation stress in the layer.

\subsection{Asaoka method [2]}

This method is based on the one-dimensional settlements $\delta_{0}, \delta_{1}, \delta_{2} \ldots$ etc. at times $0, \Delta t$, $2 \Delta t$...etc. which can be expressed as a first order approximation that represents a line written as $\delta_{n-1}=\mathrm{f}\left(\delta_{n}\right)$, known as the Asaoka graph [3, 6] (Fig. 7):

$$
S_{n+1}=\beta_{0}+\beta_{1} S_{n}
$$

Where: $\beta_{0}$ represents the intercept and $\beta_{1}$ the slope of the line (Fig. 7).

When the primary ultimate settlement is reached, $\delta_{n}=\delta_{n-1}=\delta_{u l t}$, it is written as:

$$
S_{u l t}=\beta_{0} /\left(1-\beta_{1}\right)
$$


And the settlement $S(t)$ at time $t$ can be computed as:

$$
S(\mathrm{t})=\left(\frac{\beta_{0}}{1-\beta_{1}}\right)-\left[\frac{\beta_{0}}{1-\beta_{1}}-S_{0}\right] \beta_{1}^{\mathrm{t}}
$$

Where: $S_{0}$ is the initial settlement.

In Eq. (10), $S_{0}$ must be determined first. The different values of $S_{0}$ lead to different values of $S(\mathrm{t})$. This is why the accuracy strongly depends on the initial time choice.

\subsection{Tan method [4]}

Tan and Chew [3] have shown that in-situ measurements of soil settlement as a function of time, expressed as $\mathrm{t} / \delta=\mathrm{f}(\mathrm{t})$ (Fig. 3, right), show the same shape as the theoretical curve of Terzaghi $(\mathrm{Tv} / \mathrm{U}=\mathrm{f}(\mathrm{Tv})$, Fig. 3, left). This is why these authors proposed to extrapolate this property to identify levels at $60 \%$ and $90 \%$ of consolidation for any settlement dataset.

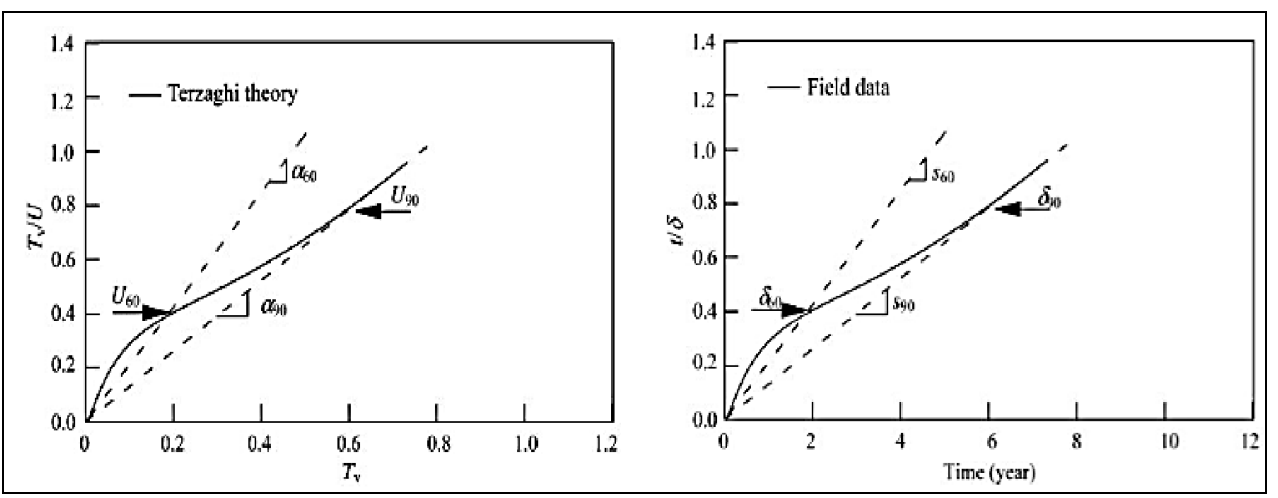

Fig. 3. Hyperbolic curve of Terzaghi (left) and in-situ measurements as a function of time (right) [3].

The $S_{60}$ and $S_{90}$ slopes can be found by:

$$
\begin{aligned}
& S_{60}=S_{i} \frac{\propto_{60}}{\propto_{\mathrm{i}}} \\
& S_{90}=S_{i} \frac{\propto_{90}}{\propto_{\mathrm{i}}}
\end{aligned}
$$

Where: $S_{\mathbf{i}}$ is the slope of the initial linear portion of the graph $t / \delta=\mathrm{f}(t)$ and $\alpha_{i}$ the slope of the theoretical graph $T v / U=\mathrm{f}(T v)$ (Fig. 3, left).

Finally, Tan and Chew [3] showed that the primary final settlement can be obtained using one of the following three ratios:

$$
\delta_{f}=\frac{\propto_{\mathrm{i}}}{S_{i}}=\frac{\delta_{60}}{0.6}=\frac{\delta_{90}}{0.9}
$$

And the settlement $\delta(t)$ can be computed as follow: 


$$
\frac{t}{\delta(t)}=\left(\frac{1}{6}\right) \frac{S_{i}}{\alpha_{\mathrm{i}}}
$$

However, according to Chunlin [6] the Tan method limitation resides mainly, also, in the determination of the initial time.

\subsection{Chunlin method [6]}

Chunlin [6] blames Asaoka and Tan methods [2, 4] to include parameters difficult to determine accurately, particularly the choice of the initial time. Chunlin [6] begins with the calculation of settling time from the one-dimensional consolidation equation of Terzaghi, by writing:

$$
S_{t}=S_{\infty}\left(1-\frac{8}{\pi^{2}} \mathrm{e}^{\mathrm{b} t}\right)
$$

Where: $S_{t}$ : settlement at time $\mathrm{t}$

$S_{\infty}$ : final settlement,

b: parameter given by in situ data or by Asaoka method.

To simplify calculations, Chunlin [6] introduces a new variable called "potential settlement" by writing:

$$
S_{p}=S_{\infty} \frac{8}{\pi^{2}} \mathrm{e}^{\mathrm{b} t}=S_{\infty}-S_{t}
$$

Where: $S_{p}$ is the potential settlement to happen in the future.

In Eq. (16), $S_{\infty}$ comes from the Terzaghi's theory. The parameter b represents the drainage conditions in the Terzaghi's consolidation equation. It may be obtained using the $C_{v}$ consolidation coefficient and the length of the drainage under various types of drainage. These two parameters must be determined first [6].

From Eq. (16) we can deduce the logarithm $\ln \left[S_{p} \pi^{2} /\left(8 * S_{\infty}\right)\right]=$ b·t which is a straight line equation of slope b (Fig. 9).

\section{Case study}

\subsection{Geological framework}

A geological and geotechnical investigation program was carried out in order to adequately characterize the geological formations and to obtain the respective geotechnical parameters of the railway [7].

In lithostratigraphic terms, the main geological formations crossed in the section between the $\mathrm{Pk} 235+100$ and the $\mathrm{Pk} 250+100$ of the railway line are characterized by ancient formations of the Miocene and Pliocene, covered by quaternary formations (Fig. 2). In summary, the Miocene (Mi) is characterized by formations of green marls while the Pliocene $(\mathrm{Pc})$ is represented by thick formations of encrusted conglomerates of limestone and gypsum. Finally the Quaternary (Qt) is characterized by formations of calcareous and calcaro-gypsum crusts [7]. 


\subsection{Geotechnical framework}

In situ investigations and laboratory tests were carried out all along the route of the railway line. The results for the studied area in PK245 zone showed the following facts [7].

In summary, two layers of soil were found. A $5 \mathrm{~m}$ layer of wet sandy clay followed by a $15 \mathrm{~m}$ saturated layer of gypsum clay (Fig. 4 and Fig. 5).

Table 1. Physical characteristics of the wet sandy clay layer (mean values) [7].

\begin{tabular}{|c|c|c|c|c|c|c|c|c|c|c|c|}
\hline \multirow[b]{2}{*}{ Parameter } & \multicolumn{9}{|c|}{ Granulometry } & \multicolumn{2}{|c|}{ Classification } \\
\hline & $\mathrm{D}_{\max }$ & \multicolumn{2}{|c|}{0.2} & 0.8 & \multicolumn{2}{|c|}{0.02} & \multicolumn{3}{|c|}{0.002} & GTR & UIC \\
\hline Unit & $\mathrm{mm}$ & \multicolumn{2}{|c|}{$\%$} & $\%$ & \multicolumn{2}{|c|}{$\%$} & \multicolumn{3}{|c|}{$\%$} & \multirow{5}{*}{$\mathrm{A}_{3}$} & \multirow{5}{*}{$\mathrm{Q}_{\mathrm{s} 0}$} \\
\hline Values & 10 & \multicolumn{2}{|c|}{95} & 62 & 5 & & & 0 & & & \\
\hline Parameter & $\omega$ & $\gamma_{\mathrm{h}}$ & $\gamma_{\mathrm{d}}$ & vbs & E & $\mathrm{w}_{1}$ & $\mathrm{w}_{\mathrm{p}}$ & $\mathrm{I}_{\mathrm{p}}$ & $\mathrm{I}_{\mathrm{c}}$ & & \\
\hline Unit & $\%$ & $\mathrm{~g} / \mathrm{cm}^{3}$ & $\mathrm{~g} / \mathrm{cm}^{3}$ & $\mathrm{~g} / 100 \mathrm{~g}$ & $\mathrm{KPa}$ & $\%$ & $\%$ & $\%$ & $\%$ & & \\
\hline Values & 15 & 1.78 & 1.55 & 3.73 & 0.55 & 54 & 27 & 27 & 1.5 & & \\
\hline
\end{tabular}

Table 2. Physical characteristics of the saturated of gypsum clay layer (mean values) [7].

\begin{tabular}{|c|c|c|c|c|c|c|c|c|c|c|c|}
\hline \multirow[b]{2}{*}{ Parameter } & \multicolumn{9}{|c|}{ Granulometry } & \multicolumn{2}{|c|}{ Classification } \\
\hline & $D_{\max }$ & \multicolumn{2}{|c|}{0.2} & 0.8 & \multicolumn{2}{|c|}{0.02} & \multicolumn{3}{|c|}{0.002} & GTR & UIC \\
\hline Unit & $\%$ & \multicolumn{2}{|c|}{$\%$} & $\%$ & \multicolumn{2}{|c|}{$\%$} & \multicolumn{3}{|c|}{$\%$} & \multirow{5}{*}{$\mathrm{A}_{4}$} & \multirow{5}{*}{$\mathrm{Q}_{\mathrm{s} 0}$} \\
\hline Values & 30 & \multicolumn{2}{|c|}{90} & 80 & 7 & & & 62 & & & \\
\hline Parameter & $\omega$ & $\overline{\gamma_{\mathrm{h}}}$ & $\gamma_{\mathrm{d}}$ & vbs & E & $\mathrm{w}_{1}$ & $\mathrm{w}_{\mathrm{p}}$ & $\mathrm{I}_{\mathrm{p}}$ & $\mathrm{I}_{\mathrm{c}}$ & & \\
\hline Unit & $\%$ & $\mathrm{~g} / \mathrm{cm}^{3}$ & $\mathrm{~g} / \mathrm{cm}^{3}$ & $\mathrm{~g} / 100 \mathrm{~g}$ & $\mathrm{KPa}$ & $\%$ & $\%$ & $\%$ & $\%$ & & \\
\hline Values & 30 & 1.95 & 1.5 & 5.14 & 0.67 & 83 & 33 & 50 & 1.06 & & \\
\hline
\end{tabular}

From Table 1 and Table 2 we can deduce the following summaries:

- $\gamma_{\mathrm{d}}=15.5 \mathrm{KN} / \mathrm{m}^{3} \leq 16 \mathrm{KN} / \mathrm{m}^{3} \rightarrow$ low density soil,

- Plasticity index $\mathrm{I}_{\mathrm{P}}>40 \rightarrow$ very plastic,

- Consistency index Ic $>1 \rightarrow$ hard clay,

- Methylene blue value vbs $>2.5 \rightarrow$ sensitive to water.

Table 3. Compressibility characteristics of wet and saturated clay layers [7].

\begin{tabular}{|c|c|c|c|c|c|}
\hline \multirow{3}{*}{ Parameter } & \multicolumn{4}{|c|}{ Compressibility } & \multirow{2}{*}{$\frac{200 \mathrm{KPa}}{\mathrm{C}_{\mathrm{v}}\left(\mathrm{m}^{2} / \mathrm{s}\right)^{*} 10^{7}}$} \\
\hline & $\mathrm{pc}(\mathrm{KPa})$ & $\mathrm{C}_{\mathrm{c}}$ & $\mathrm{C}_{\mathrm{g}}$ & $\mathrm{C}_{\mathrm{s}}$ & \\
\hline & \multicolumn{5}{|c|}{ Wet clay layer } \\
\hline Values & 520 & 17.50 & 11.02 & 0 & 6.49 \\
\hline & \multicolumn{5}{|c|}{ Saturated clay layer } \\
\hline Values & 213 & 18.00 & 9.07 & 0 & 6.49 \\
\hline
\end{tabular}

From Table 3 we can deduce the following summaries:

- The pre-consolidation stress is $520 \mathrm{KPa}$ for the wet clay layer and $213 \mathrm{KPa}$ for the saturated clay layer,

- $\quad C_{c}=0.17 \sim 0.18 \leq 0.2$ : moderately compressible clay,

- $C_{g}=0.09 \sim 0.1$ : moderately swelling clay.

\subsection{Application to consolidation settlement Sc calculation at PK245+000}

For this case study we have selected the worst case in the Boughezoul-M'sila railway line. Namely, a portion of $15 \mathrm{~km}$ long (PK245+000) where the height of embankment arrives up 
to $15 \mathrm{~m}$, reposing on a moderately compressible soil (Fig. 4). In this section we focus only on consolidation settlement $S c$ calculation.

The other settlements (immediate, secondary and lateral) are straightforward and easy to obtain. They are taken from the master thesis work of Boudjellal [13].

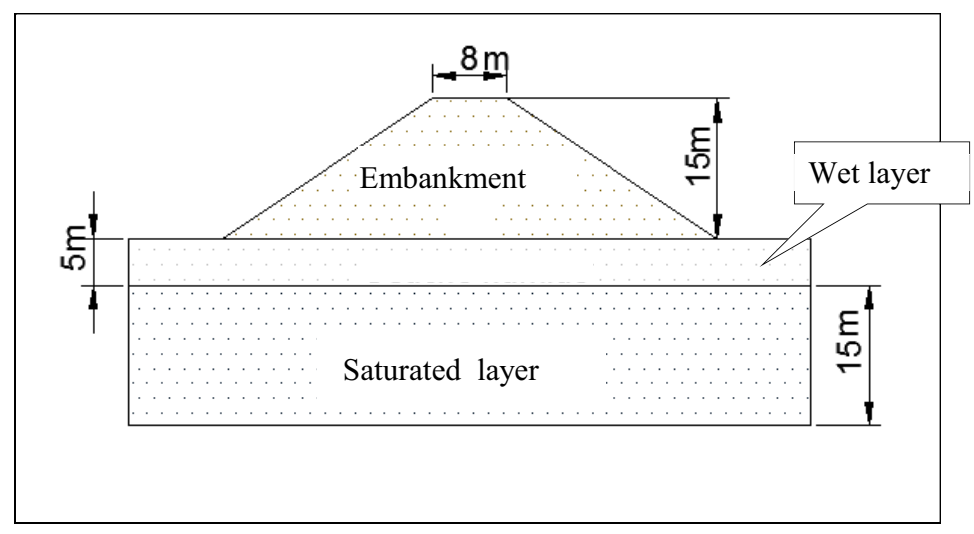

Fig. 4. Cross section with $15 \mathrm{~m}$ height embankment at PK245+000.

\subsection{1 $S_{c}$ calculation using Terzaghi's method}

We have an over-consolidated clay with $\mathrm{H} / \mathrm{B} \sim 0.3$ then $\rightarrow \quad \mu=0.6$

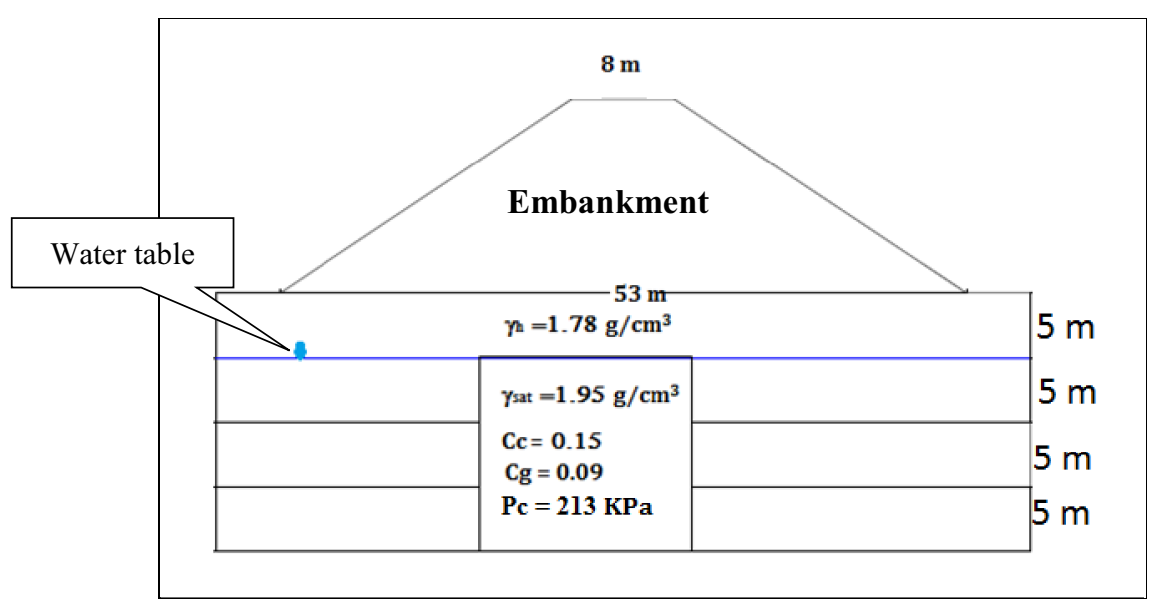

Fig. 5. Embankment profile at PK245+000.

The stress due to the embankment is given by Eq. (7), where:

$\Delta \sigma_{\mathrm{i}}=2 * I * q \quad$ and $\quad q=\gamma_{\mathrm{emb}} * \mathrm{~h}_{\mathrm{emb}}=18.50 * 15=277.5 \mathrm{KPa}$. (given that $\gamma_{\mathrm{emb}}$ and $\mathrm{h}_{\mathrm{emb}}$ are the specific weight and the height of the embankment respectively) 
Table 4 Computation of the stresses due to the embankment, Boudjellal [13].

\begin{tabular}{|c|c|c|c|c|c|}
\hline $\mathbf{H i}$ & $\mathbf{z}$ & $\mathbf{a} / \mathbf{z}$ & $\mathbf{b} / \mathbf{z}$ & $\mathbf{I}$ & $\Delta \boldsymbol{\sigma}_{\mathbf{i}}(\mathbf{K P a})$ \\
\hline 5 & - & - & - & - & - \\
\hline 5 & 7.5 & 0.53 & 3.53 & 0.5 & 277.5 \\
\hline 5 & 12.5 & 0.32 & 2.12 & 0.48 & 266.5 \\
\hline 5 & 17.5 & 0.23 & 1.51 & 0.43 & 238.5 \\
\hline
\end{tabular}

Table 5 Calculation of consolidation settlement for embankment, Boudjellal [13].

\begin{tabular}{|c|c|c|c|c|c|c|c|c|}
\hline $\begin{array}{c}\mathbf{H i} \\
(\mathbf{m})\end{array}$ & $\mathbf{e}$ & $\mathbf{C c}$ & $\mathbf{C g}$ & $\begin{array}{c}\sigma^{\prime} \mathbf{v o} \\
(\mathbf{K P a})\end{array}$ & $\begin{array}{c}\sigma^{\prime} \mathbf{p} \\
(\mathbf{K P a})\end{array}$ & $\begin{array}{c}\Delta \sigma \mathbf{i} \\
(\mathbf{K P a})\end{array}$ & $\begin{array}{c}\sigma^{\prime} \mathbf{v} \\
(\mathbf{K P a})\end{array}$ & $\begin{array}{c}\mathbf{S}_{\text {oed }} \\
(\mathbf{m})\end{array}$ \\
\hline 5 & - & - & - & - & - & - & - & - \\
\hline 5 & 0.67 & 0.21 & 0.1 & 112.75 & 213 & 277.5 & 390.25 & 0.09 \\
\hline 5 & 0.67 & 0.21 & 0.1 & 160.25 & 213 & 266.5 & 420.75 & 0.12 \\
\hline 5 & 0.67 & 0.21 & 0.1 & 207.75 & 213 & 238.5 & 446.25 & 0.17 \\
\hline \multicolumn{7}{|r|}{}
\end{tabular}

Taking into account the correction of Skempton and Bjerrum [10] with $\mu=0.6$

$$
S_{c}=\mu \cdot S_{\text {oed }}=0.6 \cdot 38.0=22.8 \mathrm{~cm}
$$

\subsubsection{Speed and consolidation time}

The relationship between the time factor $T v$ and the degree of consolidation $U v$ makes it possible to calculate the settlement corresponding to a consolidation time $t$. Conversely, in order to know the time required to reach a certain value of the settlement, the corresponding degree of consolidation is calculated and then the curve expressing $U v$ is used as a function of the time factor $T v$ according to the form of the initial distribution of the interstitial overpressure to determine $T v$ value and then the required consolidation time. We have:

$$
T_{v}=\frac{C_{v}}{\mathrm{H}^{2}} t
$$

Where: $H^{\prime}$ drainage distance $H^{\prime}=H / 2$ and $H$ the height of the compressible layer.

Table 6 Speed and settlement time calculation, Boudjellal [13].

\begin{tabular}{|c|c|c|c|c|c|}
\hline \multirow{2}{*}{$\boldsymbol{H}(\mathbf{m})$} & \multirow{2}{*}{$\boldsymbol{C} \boldsymbol{v} \mathbf{1 0}^{-7}\left(\mathbf{m}^{2} / \mathbf{s}\right)$} & $\begin{array}{c}\boldsymbol{T} \boldsymbol{v}=\mathbf{0 . 0 3 3} \\
\boldsymbol{U}=\mathbf{2 0} \%\end{array}$ & $\begin{array}{c}\boldsymbol{T} \boldsymbol{v}=\mathbf{0 . 1 9 7} \\
\boldsymbol{U} \boldsymbol{v}=\mathbf{5 0 \%}\end{array}$ & $\begin{array}{c}\boldsymbol{T} \boldsymbol{v}=\mathbf{0 . 8 4 4} \\
\boldsymbol{U} \boldsymbol{v}=\mathbf{9 0 \%}\end{array}$ & $\begin{array}{c}\boldsymbol{T} \boldsymbol{v}=\mathbf{2} \\
\boldsymbol{U}=\mathbf{9 9 . 4 \%}\end{array}$ \\
\cline { 3 - 6 } & & $t$ (years) & $t$ (years) & $t$ (years) & $t$ (years) \\
\hline 20 & 6.49 & 0.16 & 0.96 & 4.14 & 9.92 \\
\hline
\end{tabular}

Calculation results (Table 6) give a settlement time of 9 years, 11 months and 14 days: 
Table 7 Evolution of settlements over time, Boudjellal [13]

\begin{tabular}{|c|c|c|c|}
\hline Time (years) & $\boldsymbol{T} \boldsymbol{U}$ & $\boldsymbol{U}$ & Settlement $\boldsymbol{\delta}(\mathbf{c m})$ \\
\hline 0.099 & 0.02 & 0.16 & 3.648 \\
\hline 0.298 & 0.06 & 0.276 & 6.2928 \\
\hline 0.496 & 0.1 & 0.356 & 8.1168 \\
\hline 0.744 & 0.15 & 0.437 & 9.9636 \\
\hline 0.992 & 0.2 & 0.504 & 11.4912 \\
\hline 1.488 & 0.3 & 0.613 & 13.9764 \\
\hline 1.984 & 0.4 & 0.697 & 15.8916 \\
\hline 2.481 & 0.5 & 0.764 & 17.4192 \\
\hline 2.974 & 0.6 & 0.816 & 18.6048 \\
\hline 3.473 & 0.7 & 0.856 & 19.5168 \\
\hline 3.969 & 0.8 & 0.887 & 20.2236 \\
\hline 4.466 & 0.9 & 0.912 & 20.7936 \\
\hline 4.962 & 1 & 0.931 & 21.2268 \\
\hline 9.924 & 2 & 0.994 & 22.6632 \\
\hline
\end{tabular}

Using Table 7 we obtained the hyperbolic curve in Fig. 6.

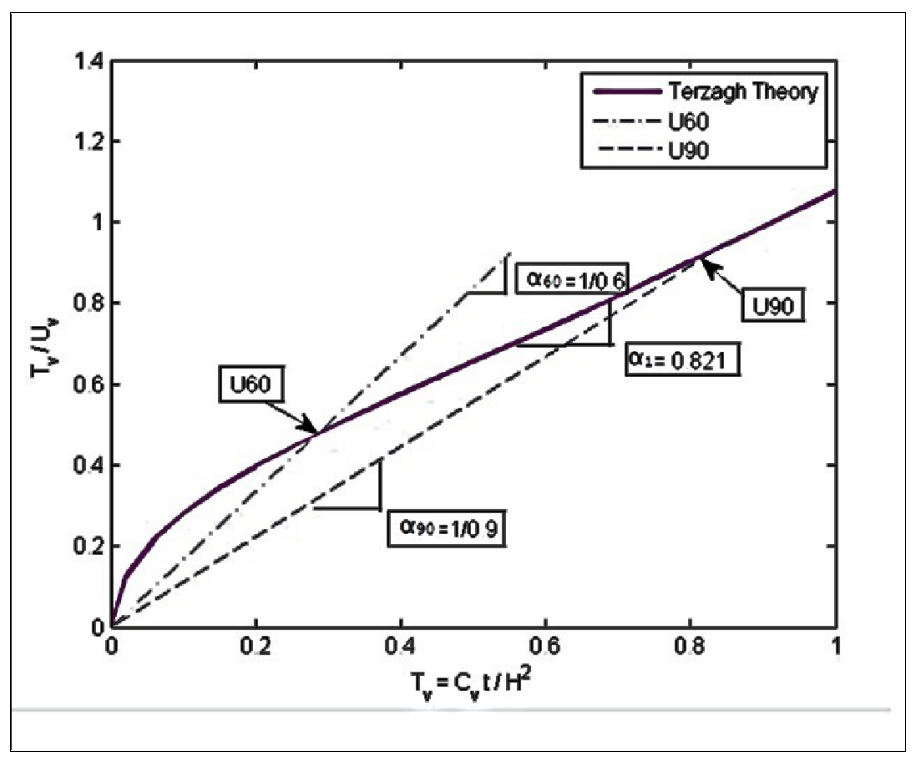

Fig. 6. Hyperbolic curve of settlements, at PK245+000, according to Terzaghi's theory.

\subsection{3 $S_{c}$ calculation using Asaoka method}

The Asaoka method [2] considers only successive settlements. Table 8 shows the successive settlements $S_{\mathrm{n}}$ and $S_{\mathrm{n}+1}$ obtained from the settlement table as a function of time (Table 7). 
Table 8 Successive settlements obtained using Table 7, Boudjellal [13].

\begin{tabular}{|c|c|c|c|}
\hline $\left.\mathbf{S}_{\mathbf{n}} \mathbf{( c m}\right)$ & $\mathbf{S}_{\mathbf{n}+\mathbf{1}}(\mathbf{c m})$ & $\mathbf{S}_{\mathbf{n}} \mathbf{( c m )}$ & $\mathbf{S}_{\mathbf{n}+\mathbf{1}}(\mathbf{c m})$ \\
\hline 3.648 & 6.2928 & 15.8916 & 17.4192 \\
\hline 6.2928 & 8.1168 & 17.4192 & 18.6048 \\
\hline 8.1168 & 9.9636 & 18.6048 & 19.5168 \\
\hline 9.9636 & 11.4912 & 19.5168 & 20.2236 \\
\hline 11.4912 & 13.9764 & 20.2236 & 20.7936 \\
\hline 13.9764 & 15.8916 & 20.7936 & 21.2268 \\
\hline
\end{tabular}

Graphical determination of settlement (Fig. 7):

$$
S_{n+1}=\beta_{0}+\beta_{1} S_{n}
$$

Where:

Which gives:

$$
\beta_{0}=\frac{\Delta\left(S_{n^{+1}}\right)}{\Delta S_{n}}=0.7772 \quad \text { and } \quad \beta_{1}=5.0646
$$

And finally

$$
S_{c}=\beta_{0} /\left(1-\beta_{1}\right)=22.73 \mathrm{~cm}
$$

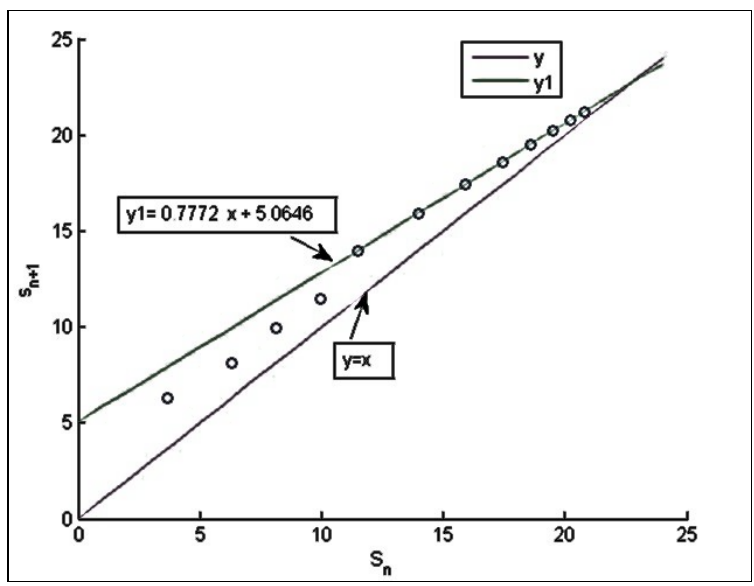

Fig. 7. Asaoka curve for PK245+000 railway embankment, Boudjellal [13].

\subsection{4 $S_{c}$ calculation using Tan hyperbolic method}

Using the $C v$ value obtained previously (Table $6, C v=6.4910^{-7} \mathrm{~m}^{2} / \mathrm{s}$ ) we plotted the $t=\mathrm{f}(\mathrm{t} / \delta)$ curve from the calculation data in following Table 9.

Using the curve in Fig. 8, Tan method [4] emphasizes on the linear part of the graph (between $\delta_{60}$ and $\delta_{90}$ ) which is written as:

$$
\frac{t}{\delta}=\alpha \cdot \delta+\beta
$$

Where $\alpha$ and $\beta$ are determined graphically: $\alpha=\frac{\Delta\left(\frac{t}{\delta}\right)}{\Delta t}=0.0405$ and $\beta=0.0349$ Then:

$$
\begin{aligned}
& \frac{\mathrm{t}}{\delta}=0.0405 * \delta+0.0349 \\
& S_{\mathrm{c}}=\frac{\alpha_{\mathrm{i}}}{\mathrm{s}_{\mathrm{i}}}=\frac{0.82}{0.0405}=20.25 \mathrm{~cm}
\end{aligned}
$$

We obtain

Table 9 Settlement according to time/settlement ratio obtained from Table7, Boudjellal [13]. 


\begin{tabular}{|c|c|c|c|}
\hline $\mathbf{t}$ (years) & $\mathbf{t} / \boldsymbol{\delta}$ (years/cm) & $\mathbf{t}$ (years) & $\mathbf{t} / \boldsymbol{\delta}$ (years/cm) \\
\hline 0,099 & 0,027 & 2,481 & 0,142 \\
\hline 0,297 & 0,047 & 2,977 & 0,160 \\
\hline 0,496 & 0,061 & 3,473 & 0,177 \\
\hline 0,744 & 0,074 & 3,969 & 0,196 \\
\hline 0,992 & 0,086 & 4,466 & 0,214 \\
\hline 1,488 & 0,106 & 4,962 & 0,233 \\
\hline 1,984 & 0,124 & 9,924 & 0,437 \\
\hline
\end{tabular}

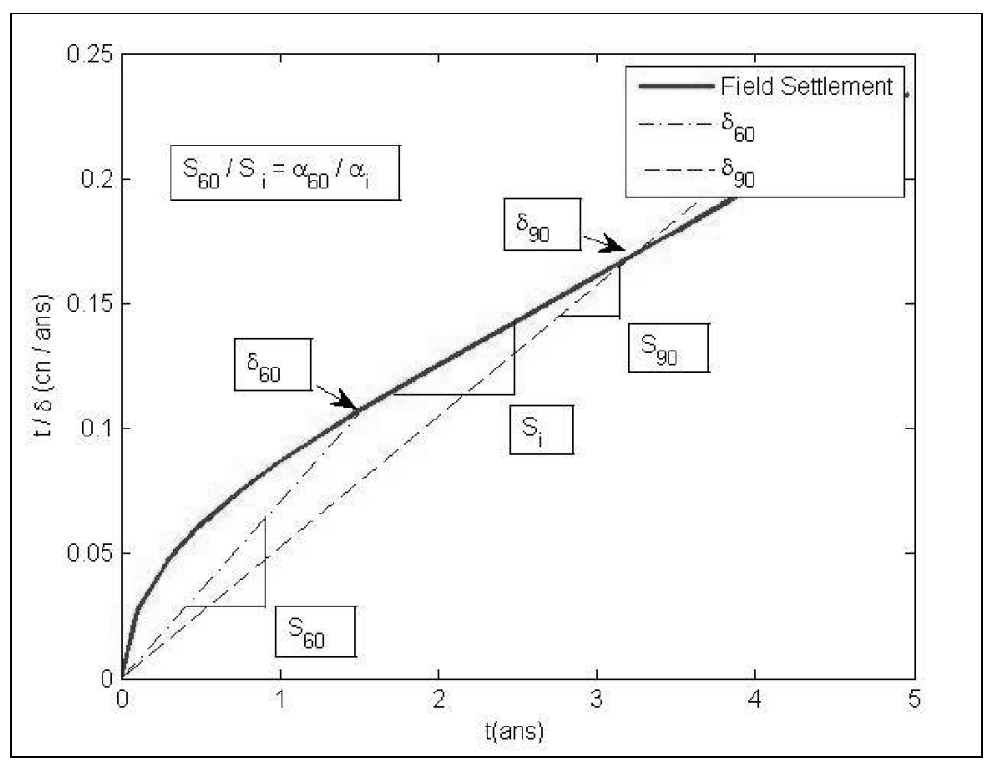

Fig. 8. Tan Hyperbolic curve for embankment settlement at Pk245+000.

\subsection{5 $\mathrm{S}_{c}$ calculation using Chunlin method}

The graph of Fig. 9 gives the slope of the line $b=-0.0014$ and according to the hypothesis of Chunlin [6] the final settlement $S_{\infty}=59.08 \mathrm{~cm}$ (Table 11) is the same as the Terzaghi's method.

Table 10 Calculations using Chunlin method [6] at PK245+000.

\begin{tabular}{|c|c|c|c|}
\hline$t$ (years) & $\operatorname{Ln}\left(\left(S p * \pi^{2}\right) /\left(8 * S_{\infty}\right)\right)$ & $t$ (years) & $\operatorname{Ln}\left(\left(S p * \pi^{2}\right) /\left(8 * S_{\infty}\right)\right)$ \\
\hline 36.225 & 0.036 & 905.639 & -1.234 \\
\hline 108.672 & -0.113 & 1086.767 & -1.483 \\
\hline 181.127 & -0.23 & 1267.895 & -1.728 \\
\hline 271.691 & -0.364 & 1449.023 & -1.97 \\
\hline 362.255 & -0.491 & 1630.151 & -2.22 \\
\hline 543.383 & -0.739 & 1811.279 & -2.464 \\
\hline 724.511 & -0.984 & 3622.558 & -4.906 \\
\hline
\end{tabular}


Then from Eq. (16), we obtain $S_{\mathrm{c}}$ at $t=3622.5$ days by:

$$
S_{c}=22.8 *\left(1-\frac{8}{\pi^{2}} \mathrm{e}^{-0.0014 * 3622.5}\right)=22.78 \mathrm{~cm}
$$

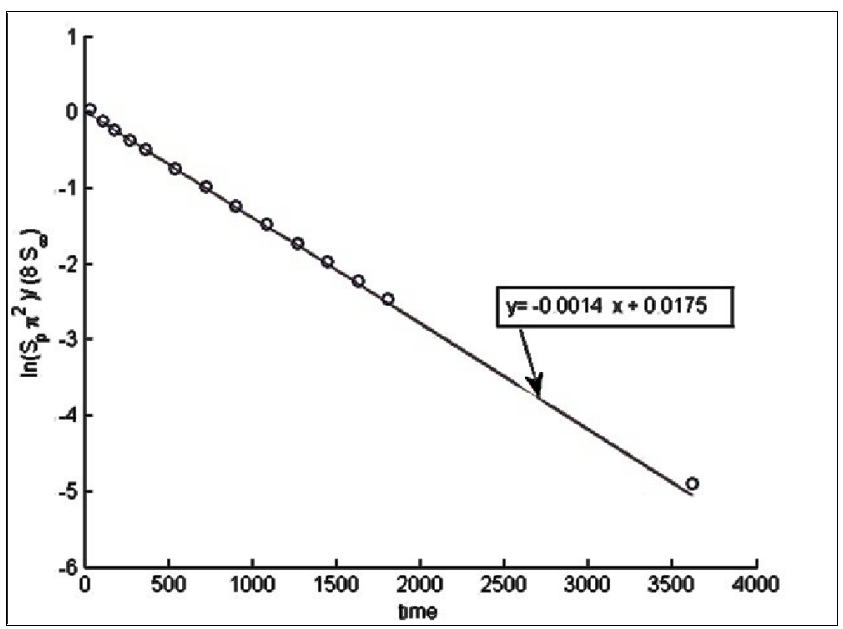

Fig. 9. Chunlin curve for railway embankment at PK245+000.

\section{Results and discussion}

The calculation results of consolidation settlement, $S_{\mathrm{c}}$ at PK245+000, according to the four methods studied in this work are summarized in Table 11 below. To make the comparison more interesting we also presented the other types of settlements (initial, secondary and lateral) as well as final settlement $S_{\infty}$ as calculated by Boudjellal [13] for the same embankment of the Boughezoul-M'sila railway project.

These results show a nearly identical final settlement $S_{\infty}$ regardless of the method. This is predictable since all these methods are based, in their calculations, on the final settlement of Terzaghi. But regarding consolidation settlement $S_{\mathrm{c}}$, which is the subject of this study, we note that the results obtained are almost, also, similar between the different methods.

However, the methods of Chunlin [6] and Asaoka [2] are the most interesting because they are more experimental (graph of successive settlements), simple, easy and free of subjective parameters. On the other hand, the method of Terzaghi [1] remains rather long and empirical whereas the Tan method [4] suffers mostly from the choice of the initial time which can distort the results if inaccurate. Moreover, these results confirm those obtained by Chunlin [6] in his research, particularly at the end of the settlement period.

Table 11. Result of Sc settlement calculation at PK245+000 according to the four methods.

\begin{tabular}{|c|c|c|c|c|c|}
\hline \multirow[t]{2}{*}{ Method } & \multicolumn{4}{|c|}{ Different settlements (cm) } & \multirow{2}{*}{$\begin{array}{c}\text { Final settlement after } 9 \text { years } \\
S_{\infty}(\mathrm{cm})\end{array}$} \\
\hline & $S_{\mathrm{i}}$ & $S_{\mathrm{c}}$ & $S_{\mathrm{s}}$ & $S_{\text {lat }}$ & \\
\hline Terzaghi & \multirow{4}{*}{26.83} & 22.80 & \multirow{4}{*}{6.3} & \multirow{4}{*}{3.15} & 59.08 \\
\hline Asaoka & & 22.73 & & & 59.01 \\
\hline Tan & & 20.75 & & & 57.03 \\
\hline Chunlin & & 22.78 & & & 59.06 \\
\hline
\end{tabular}




\section{Conclusion}

Knowing that the case study we have dealt with is a high embankment $(15 \mathrm{~m})$ on a railway track, where the tolerances to settlement errors are of the order of $\mathrm{mm}$; this work has been particularly interesting. Therefore, we applied the four methods, Terzaghi [1], Asaoka [2], Tan [4] and Chunlin [6], to estimate consolidation settlement of the embankment in question. All of these methods showed very close results, within a few tenths of a millimetre.

We can conclude that for the estimation of an intermediate phase settlement, which could prove crucial in certain projects such as railways, the new Chunlin method [6] is particularly attractive by its simplicity and precision. This method, together with Asaoka method [2], is even more precise for intermediate settlement calculation, as shown by Boudjellal [13]. Meanwhile for the final settlement all four methods are comparable. This is explained by the fact that they all are theoretically based on Terzaghi's assumptions and use the same $S_{\infty}$ value. However, in the intermediate phase the precision of the Asaoka or Chunlin methods $[2,6]$ is explained by the fact that these two methods are much more based on the experimental side than the empirical one, as opposed to the two other methods.

\section{References}

1. K. Terzaghi, Principles of soil mechanics, Settlement and consolidation of clay. Eng. N. R., 95, pp874-878 (1925)

2. A. Asaoka, Observational procedure of settlement prediction. $S$. and F., $18 \mathrm{pp} \mathrm{87-101}$ (1978)

3. S. Tan, S. Chew, Comparison of the hyperbolic and Asaoka observation method of monitoring consolidation with vertical drains. S. F., 36, pp31-42 (1996)

4. S. Tan, Validation of hyperbolic method for settlement in clays vertical drains. $S$. $F$., 35, pp101-113 (1995)

5. S. Tan, Hyperbolic method for settlements in clays with vertical drains. Can. Geo. J. 31, pp125-131 (1994)

6. L. Chunlin, A simplified method for prediction of embankment settlement in clays. $J$. R. M. Geo. China, pp61-66 (2014)

7. SETIRAIL, Rapport géotechnique projet ferroviaire Boughezoul-M'sila, lot 1, dossier 302, Algeria (2011)

8. G. Costet, J. Sanglerat, Cours de mécanique des sols 1, Plasticité et calcul des tassements. Troisième édition, Dunod, 277p, Paris (1981)

9. F. Bourges, C. Mieussens, Déplacements latéraux à proximité des remblais sur sols compressibles. Méthodes de prévision. Bull. L. L.P.C. 101, pp73-100, Paris (1979)

10. A. W. Skempton, L. Bjerrum, A contribution to the settlement analysis of foundations on clay. Géotech. 7, pp168-178 (1957)

11. Y. Akou, Etude expérimentale et modélisation de l'élargissement des remblais sur sols. PhD thesis, ENPC, 254p, France (1995)

12. S. Leroueil, J. P. Magnan, F. Tavenas, Remblais sur argiles molles. Technique et documentation - Lavoisier, 342p, Paris (1985)

13. M. Boudjellal, Etude comparative des méthodes d'estimation des tassements des remblais de voie ferrée de grandes hauteurs. Master Thesis. ENSTP, Algeria (2015) 